\title{
ISOLATION, IDENTIFICATION, AND ANTIOXIDANT ACTIVITY OF CHEMICAL COMPOUND IN ETHANOL EXTRACT OF PAPAYA LEAVES (CARICA PAPAYA L.)
}

\author{
YUNAHARA FARIDA*, ISWAHYUNI ISWAHYUNI \\ Department of Chemistry, Faculty of Pharmacy, University of Pancasila, Jakarta, Indonesia. Email: yunahara_farida@yahoo.com
}

Received: 14 October 2017, Revised and Accepted: 14 February 2018

ABSTRACT

Objective: The purpose of this research was to isolate and identify the active antioxidant compound in ethanol extract of papaya leaves (Carica papaya L.).

Methods: The methods used were fractionation using vacuum liquid chromatography (VLC), and the active fraction was purified using column chromatography (CC). The pure isolate was obtained with preparative thin-layer chromatographic (TLC) identified by spectroscopy. Its antioxidant activity was evaluated using 2,2-diphenyl-picryl-hydrazyl. The presence of phenols was analyzed using ultraviolet (UV)-visible, Fourier-transform infrared (FTIR), and gas chromatography (GC)-mass spectrometry (MS).

Results: The results showed that ethanol extract of papaya leaf has a strong antioxidant activity with $\mathrm{IC}_{50}$ value of $100.0 \pm 0.07$ ppm. The result of VLC fractionation using mobile phase of chloroform-methanol indicated that the active fraction was EtOH. 3 that has antioxidant activity with $\mathrm{IC}_{50}$ of $121.6 \pm 0.66 \mathrm{ppm}$. The purification using CC produced active fraction EtOH.3.3 with $\mathrm{IC}_{50}$ value of $176.4 \pm 0.76 \mathrm{ppm}$. After identified, the active isolate compound EtOH.3.3.1 from preparative TLC, the results of UV-visible spectrophotometry, FTIR spectrophotometry, and GC-MS show the presence of the phenol compounds.

Conclusion: The ethanol extract has antioxidant activity and the extract was suspected to contain 2-methoxy-4-vinylphenol compound.

Keywords: Papaya leaves, Antioxidant activity, Active compound, Fractionation.

(C) 2018 The Authors. Published by Innovare Academic Sciences Pvt Ltd. This is an open access article under the CC BY license (http://creativecommons. org/licenses/by/4. 0/) DOI: http://dx.doi.org/10.22159/ajpcr.2018.v11s1.26583

\section{INTRODUCTION}

Free radicals are molecules that contain one or more unpaired electrons in their outer orbital, very reactive and unstable. In an attempt to achieve their stable state, the free radicals will react with atoms or molecules around it to obtain electron pairs [1]. Free radical formation cannot be avoided; therefore, our bodies need an antioxidant. Antioxidant is a neutralizer of free radicals in the body and can inhibit oxidation. This substance is needed in the body to combat the trigger of chronic disease caused by free radicals. Natural antioxidants can be obtained from fruits and vegetables one of them is papaya (Carica papaya L.). In addition to the fruit used by the community as food, almost all parts of papaya plants can be used as a natural remedy. Many reports have also shown that the leaves of $C$. papaya have activity as an anticancer [2], antimicrobial [3-6], anti-inflammatory [7], analgetic activity [8], antiplasmodial or antimalarial activity [9-11], and antioxidant [12-14]. Papaya leaves water extract is proved as dengue fever drug $[15,16]$. The purpose of this research was to isolate and identify the active antioxidant compound in ethanolic extract of papaya leaves (C. papaya L.).

\section{METHODS}

\section{Materials}

Papaya leaves (C. papaya L.) were collected in Balittro, Bogor, Indonesia, ethanol, methanol, n-hexane, ethyl acetate, chloroform, Vitamin C, 1,1-diphenyl-2-picrylhydrazyl (DPPH), silica gel 60, Sephadex LH20, $30 \%$ ammonia, hydrochloride acid, $1 \%$ iron (III) chloride, Dragendorff's reagent, Mayer reagent, and Stiasny reagent.

Rotary vacuum evaporator, chromatographic columns, ultraviolet (UV) lamps, chamber, GF254 silica gel plates, UV-visible spectrophotometry, Fourier-transform infrared (FT-IR) spectrometer, and gas chromatography-mass spectrometry (GC-MS) were used.

\section{Extraction}

About $1 \mathrm{~kg}$ of dried powder of $C$. papaya leaves was extracted with n-hexane, ethyl acetate, and ethanol by maceration method at room temperature for $24 \mathrm{~h}$ ( 3 times), then collected solution was filtered. The crude ethanolic solution was subsequently concentrated using rotary vacuum evaporator. The ethanol extract was ready for further analysis.

\section{Phytochemical screening}

Phytochemical screening is meant to identify compounds such as flavonoids by the reduction test ( $\mathrm{Mg}-\mathrm{HCl} / \mathrm{amyl}$ alcohol), saponins by the foam formation test, tannins by the iron (III) chloride reagent, quinones by the $\mathrm{NaOH}$ reagents, steroids/triterpenoids by the LiebermannBurchard's reagent, alkaloids by the Dragendorff's reagent/Mayer reagent, coumarins by the fluorescence test with ammonia, and essential oils by the odor test, based on the method of Farnsworth [18,24].

\section{Thin-layer chromatographic (TLC) analysis}

The ethanol extract was analyzed by TLC method using silica gel $\mathrm{GF}_{254}$ with three solvents mixture:n-hexane-ethyl acetate $(9: 1,4: 1)$, ethyl acetate-methanol $(3: 7,4: 6)$, and chloroform-methanol $(7: 3,6: 4)$. The spots were visually identified under $254 \mathrm{~nm}$ and $366 \mathrm{~nm}$ UV lamp. The solvent that produced good separation on TLC chromatograms was chosen for vacuum liquid chromatography (VLC) and then used in TLC monitoring of fractions taken from column chromatography (CC).

\section{Antioxidant activity test}

The antioxidant activity of C. papaya extract was determined by the method of William et al. [19] and Blois [20] with slight modification using the stable DPPH scavenging. Briefly, samples extract with various concentrations was prepared $30,60,90,120$, and $150 \mu \mathrm{g} / \mathrm{mL}$. Each sample was mixed with $1.0 \mathrm{~mL}$ of $0.4 \mathrm{mM}$ DPPH solution. All the solutions were prepared with methanol to $5.0 \mathrm{~mL}$. Experiment was done in triplicate. The test sample was incubated for $30 \mathrm{~min}$ at room temperature and the absorbance was measured at $517 \mathrm{~nm}$. Ascorbic acid 
was used as a standard at concentration of $2,4,6,8$, and $10 \mu \mathrm{g} / \mathrm{mL}$ and DPPH in methanol was used as a control. The different in absorbance between the test and the control was calculated and the expressed as \% scavenging of DPPH radical (\% inhibitions). Then, \% inhibitions were plotted against respective concentration used and from the graph $\mathrm{IC}_{50}$ was calculated.

\section{Fractionation}

The ethanol extract was separated on silica gel 60 using VLC with a step gradient elution of following composition chloroform-methanol with a ratio as shown in Table 1 . All of the fractions were tested antioxidant using DPPH scavenging method. The active fractions were further purified by CC. The stationary phase was made up of glass column packed using Sephadex LH20 with methanol as mobile phase. The chemical composition of fraction was evaluated using TLC and visualized with UV (254 $\mathrm{nm}$ and $366 \mathrm{~nm}$ ).

\section{Purification and identification}

Purification was conducted using TLC preparative $\left(\mathrm{SiO}_{2}\right.$, chloroformmethanol=6:4). Furthermore, the identification by UV-visible spectrophotometer, FTIR spectrometer, and GC-MS.

\section{RESULTS AND DISCUSSION}

Phytochemical screening of the ethanol extract of $C$. papaya leaves contains flavonoids, tannins, alkaloids, and steroids/triterpenoids.

The antioxidant activity of ethanol extract of papaya leaves has a strong antioxidant activity with $\mathrm{IC}_{50}$ value of $100.0 \pm 0.07 \mathrm{ppm}$. Crude extract with $\mathrm{IC}_{50}$ values $<200$ ppm showed mild antioxidant activity. The $\mathrm{IC}_{50}$ is the concentration of antioxidant activity to scavenge DPPH free radical $50 \%$. Vitamin $\mathrm{C}$ as positive control has highest antioxidant activity that Vitamin $\mathrm{C}$ has the power of attenuation against free radicals with $\mathrm{IC}_{50}$ value of $2.4 \mathrm{ppm}$. VLC results obtained nine fractions, using a mobile phase chloroform-methanol (Table 1), whereas the mobile phase used for the TLC analysis of fraction using chloroform-methanol (6:4) which gave the best separation. Antioxidant activity test results to see percentage of inhibition for the all fractions using concentration of 120 ppm are given in Fig. 1.

Based on the data (Fig. 1) showed that the EtOH.3 fraction had the largest \% inhibition (67.91\%), indicates that the EtOH.3 fraction is the most powerful fraction of its activity. Next, the fraction was tested for antioxidant activity, results showed $\mathrm{IC}_{50}$ value of $121.6 \pm 0.66 \mathrm{ppm}$. According to Blois [20], in Hanani et al. [21], a substance can be expressed to be a strong antioxidant if it has an $\mathrm{IC}_{50}$ value $<200 \mathrm{ppm}$, thus EtOH.3 is a fraction that has antioxidant capabilities such as those associated with phytochemical screening results that include flavonoids. Flavonoids have been studied to have various activities such as antioxidants and antibacterials [17].

The EtOH.3 fraction was further purified by CC using Sephadex LH20 as stationary phase and methanol as a mobile phase. The purification using CC produced six fractions. Monitoring of fractions obtained from CC was performed by TLC method (silica gel $\mathrm{GF}_{254}$, chloroformethanol=6:4). Furthermore, the fractions tested the antioxidant activity using DPPH free radical to determine the most active fraction to be identified further. The results showed in Table 2 .

The fraction of EtOH.3.3 is the most active fraction was further purified by preparative TLC (silica gel $\mathrm{GF}_{254}$, chloroform-ethanol=6:4) to get pure isolate. The chromatogram that obtained of preparative TLC can be seen in Fig. 2.

The possibility of antioxidant activity decreases due to the content of nutritious compounds as an increasingly weakened antioxidant and reduced synergistic compounds that increase antioxidant activity because isolates are thought to have been a single compound. This is in accordance with the theory of secondary efficacy enhancing substance.
Table 1: VLC fractionation of ethanol extract papaya leaves

\begin{tabular}{llll}
\hline No. & Fraction & $\begin{array}{l}\text { Solvent for } \\
\text { VLC (chloroform-methanol }\end{array}$ & Weight (g) \\
\hline 1. & EtOH.1 & $90: 10$ & 0.1019 \\
2. & EtOH.2 & $80: 20$ & 1.5487 \\
3. & EtOH.3 & $70: 30$ & 1.1380 \\
4. & EtOH.4 & $60: 40$ & 1.1034 \\
5. & EtOH.5 & $50: 50$ & 2.2428 \\
6. & EtOH.6 & $40: 60$ & 2.4207 \\
7. & EtOH.7 & $30: 70$ & 1.3738 \\
8. & EtOH.8 & $20: 80$ & 2.8902 \\
9. & EtOH.9 & $10: 90$ & 1.1157 \\
\hline
\end{tabular}

VLC: Vacuum liquid chromatography

Table 2: Percentage of inhibition and $\mathrm{IC}_{50}$ of the EtOH.3 fraction

\begin{tabular}{llll}
\hline No. & Fraction & Inhibition (\%) & IC $_{\mathbf{5 0}} \mathbf{( p p m )}$ \\
\hline 1. & EtOH.3.1 & 31.2 & $176.4 \pm 0.76$ \\
2. & EtOH.3.2 & 44.97 & \\
3. & EtOH.3.3 & 60.35 & \\
4. & EtOH.3.4 & 41.92 & \\
5. & EtOH.3.5 & 56.32 & \\
6. & EtOH.3.6 & 52.32 & \\
\hline
\end{tabular}

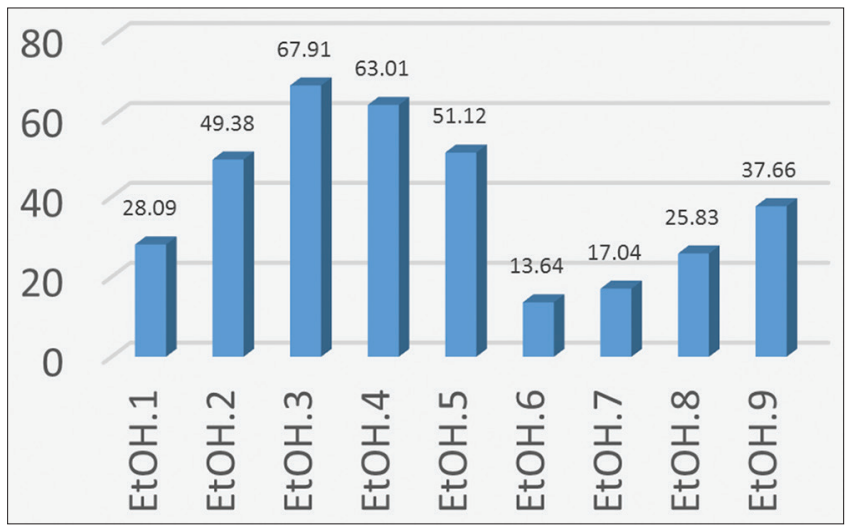

Fig. 1: The \% inhibition 2,2-diphenyl-picryl-hydrazyl of the nine fractions ethanol extract from vacuum liquid chromatography

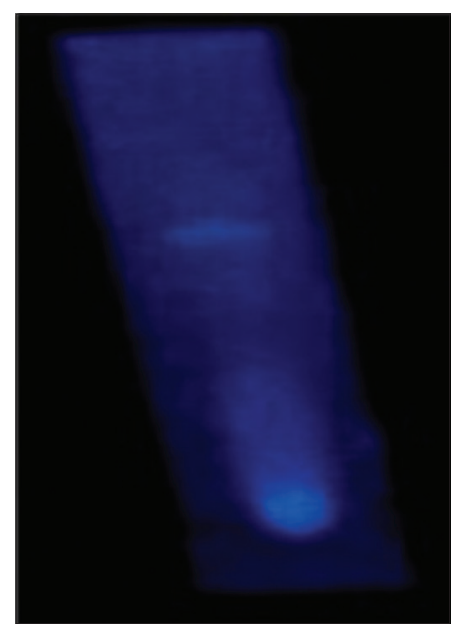

Fig. 2: Chromatogram of preparative thin-layer chromatographic Et0H.3.3 fraction

Based on Table 1, ethanol extract of papaya leaves has a moderate strength of antioxidant activity with $\mathrm{IC}_{50}$ value of $100.0 \pm 0.07 \mathrm{ppm}$, the EtOH.3 fraction from VLC showed decreased antioxidant activity 
compared with $\mathrm{IC}_{50}$ produced by ethanol extract with $\mathrm{IC}_{50}$ value of $121.6 \pm 0.66 \mathrm{ppm}$. Based on Table 2, the EtOH.3.3 fraction produced by separation of CC yield $\mathrm{IC}_{50}$ of $176.4 \pm 0.76 \mathrm{ppm}$ which increasingly indicates weak strength of antioxidant activity contained in isolate EtOH.3.3.1 having \% inhibition of 52.83\%.

The UV-visible spectrum of isolate (Fig. 3) showed maximum wavelength at $206.0 \mathrm{~nm}$ with absorbance 0.7140 . The UV-visible spectrum results can be estimated by the presence of the conjugated double bond present in the compound because the maximum measured wavelength is above $200 \mathrm{~nm}$. The results of the spectrum of the isolate can be seen in Fig. 3.

The FTIR spectrum of isolate (Fig. 4) showed the presence of functional groups $\mathrm{C}=\mathrm{C}$ (aromatic ring) at $1571.88 / \mathrm{cm},-\mathrm{OH}$ (alcohol) at $3282.62 / \mathrm{cm}$, and C-O (carbonyl) at $1666.38 / \mathrm{cm}[22,23]$. These results are supported by the prediction of identification data that EtOH.3.3.1 isolates contain phenol compounds. To identify more

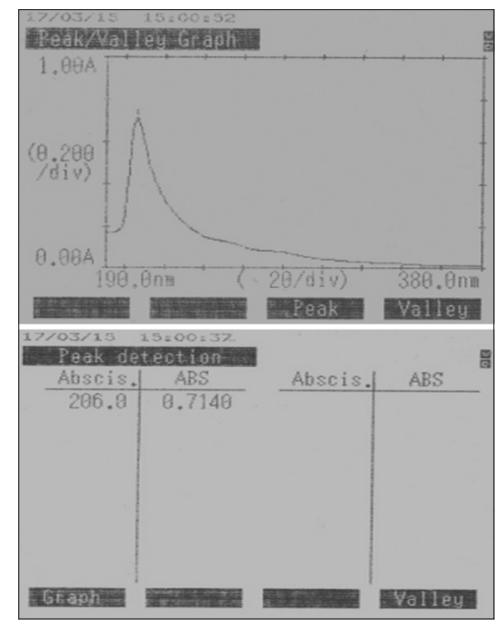

Fig. 3: Ultraviolet-visible spectrum of isolate from the EtOH.3.3.1 fraction

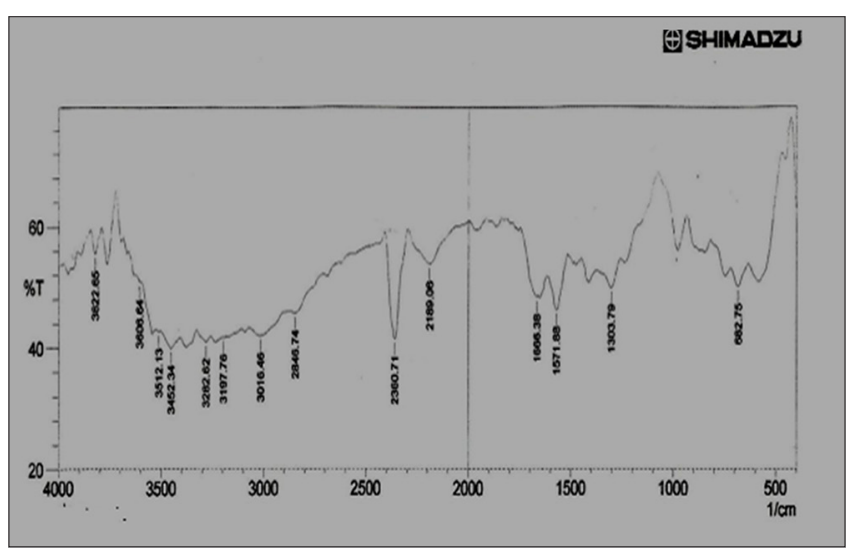

Fig. 4: Fourier-transform infrared spectrum of isolate

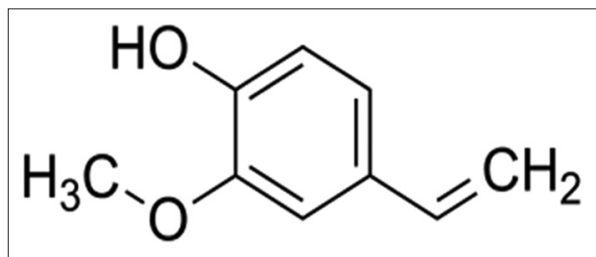

Fig. 5: Molecular structure of 2-methoxy-4-vinylphenol clearly the isolate compounds contained in EtOH.3.3.1 isolates, it is necessary to analyze using GC-MS. The isolate shows the presence of the phenol compounds with \% inhibition of $52.83 \%$. Based on this similarity, the structure of isolate was therefore predicted as 2-methoxy-4-vinylphenol (Fig. 5).

\section{CONCLUSION}

Based on the results of isolation, identification, and antioxidant activity test of the chemical compound of ethanol extract of $C$. papaya leaves, it could be concluded that

1. The ethanol extract was suspected to contain 2-methoxy-4vinylphenol compound $\left(\mathrm{C}_{9} \mathrm{H}_{10} \mathrm{O}_{2}\right)$.

2. The ethanol extract has antioxidant activity using DPPH free radical scavenging.

\section{ACKNOWLEDGMENTS}

The authors would like to thank Faculty of Pharmacy, University of Pancasila, for Laboratory facility.

\section{REFERENCES}

1. Winarsi H. Natural antioxidant and Free radicals. Yogyakarta: Kanisius; 2007. p. 15-20, 77-81.

2. Rashed K, Fouche G. Anticancer activity of Carica papaya extracts in vitro and phytochemical analysis. Greener J Pharm Pharmacol 2013;1:1-5.

3. Vijayakumar M, Bharathidasan R, Prince L. Antimicrobial activity of Carica papaya L. Int J Arts Sci Res 2015;2:37-43.

4. Brij BT, Gomathinayagam S, Rekha G. Antimicrobial properties of Carica papaya (Papaya) different leaf extract against E.coli, S.aureus and C.albicans. Am J Pharmacol Pharmacother 2013;1:25-9.

5. Nirosha N, Mangalanayaki R. Antibacterial activity of leaves and stem extract of Carica papaya L.Int J Adv Pharm Biol Chem 2013;2:473-6.

6. Farooq T. Phytochemical and Pharmacological Investigation of the Leaves of Carica papaya Linn. East West University; 2009. p. 26-37.

7. Owoyele BV, Adebuloka OM, Funmilayo AA, Soladoye AA, Antiinflammatory activities of ethanolic extract of Carica papaya leaves. Inflammopharmacology 2008;16:168-73.

8. Hasimun P, Suwendar, Ernasari GI. Analgetic activity of Papaya (Carica papaya L) leaves extract. Proc Chem 2014;13:147-9.

9. Syamsudin A, Marisi TR, Yunahara F, Made Dwi SN, Marieta DR. Phytochemical screening and antimalarial activity of some plants traditionally used in Indonesia. Asian Pac J Trop Dis 2015;5:454-7.

10. Melariri P, Campbell W, Etusim P, Smith P. Antiplasmodial properties and bioassay-guided fractionation of ethyl acetate extracts from Carica papaya leaves. J Parasitol Res 2011;2011:104954.

11. Bhat GP, Surolia N. In vitro antimalarial activity of extracts of three plants used in the traditional medicine of India. Asian Pac J Trop Dis 2001;65:304-8.

12. Esther JA, Nathaniel OW, Mercy B, Selina AS. Phytochemical screening, antimicrobial and antioxidant properties of assorted Carica papaya leaves in Ghana. J Med Plants Stud 2016;4:193-8

13. Raaman N. Thin layer chromatographic analysis and antioxidant activities of methanol extract of leaves of Carica papaya L. Int J Adv Pharm Biol Chem 2015;4:414-534.

14. Maisarah AM, Amirah BN, Asmah R, Fauziah O. Antioxidant activity of different parts of Carica papaya. Int Food Res J 2013;20:1043-8.

15. Ahmad N, Fazal H, Ayaz M, Abbasi BH, Mohammad I, Fazal L, et al. Dengue fever treatment with Carica papaya leaves extracts. Asian Pac J Trop Biomed 2011;4:330-3.

16. Subenthiran S, Choon TC, Cheong KC, Thayan R, Teck MB, Muniandy PK, et al. Carica papaya leaves juice significantly accelerates the rate of increase in platelet count among patients with dengue fever and dengue haemorrhagic fever. Evid Based Complement Alternat Med 2013;2013:616737.

17. Mohan S, Bustaman A, Ibrahim S, Al-Zubairi AS, Elhassan MM, et al. Antibacterial and antioxidant activities of Typhonium flagelliforme (Lodd) Blumetuber. Am J Biochem Biol 2008;4:402-7.

18. Farnsworth NR. Biological and phytochemical screening of plants. J Pharm Sci 1966;55:225-76.

19. William WB, Cuvelier ME, Berset C. Use of a free radical method to evaluate antioxidant activity. LWT Food Sci Technol 1995;28:25-30. 
20. Blois MS. Antioxidant determination by the use of a stable free radical. Nature 1958;26:1199-200

21. Hanani E, Abdul M, Ryany S. Identification of antioxidant compounds in Callyspongiaspons from thethousand islands. Pharm Sci Mag (Majalah Ilmu Kefarmasian) 2005;2:127-33.

22. Silverstein RM, Webster FX, Kiemle DJ. Spectrometric Identification of Organic Compounds. $7^{\text {the }}$. New York: John Wiley \& Sons, Inc.; 2005. p. 188-92, 223-4.

23. Douglas A, Skoog F, Holler J, Stanley R. Crouch, Principles of Instrumental Analysis. $6^{\text {th }}$ ed. Canada: Thomson Brooks Cole; 2007. p. 238

24. Harborne JB, Phytochemical Methods: A Guide to Modern Techniques of Plant Analysis. $2^{\text {nd }}$ ed. London: Chapman and Hall; 1984. 